\title{
Parameters of anesthesia/sedation in children receiving radiotherapy
}

\author{
Kevin P McMullen ${ }^{1,2}$, Tara Hanson ${ }^{2}$, Jennifer Bratton ${ }^{1}$ and Peter A S Johnstone ${ }^{1,3^{*}}$
}

\begin{abstract}
Background: Previous reports establish low risk of complications in pediatric treatments under anesthesia/sedation (A/S) in the outpatient setting. Here, we present our institutional experience with A/S by age and gender in children receiving daily proton $\mathrm{RT}$.

Methods: After Institutional Review Board approval, we reviewed our center's records between 9/9/2004 and 6/30/2013 with respect to age and gender of A/S requirement in our pediatric patients (defined as patients $\leq 18$ years of age).

Results: Of 390 patients treated in this era, 182 were girls. Children aged $\leq 3$ invariably required A/S; and by age 7-8, approximately half of patients do not. For pediatric patients $\geq 12$ years of age, approximately $10 \%$ may require A/S for different reasons. There was no difference by gender.

Conclusions: Beyond age 3, the requirement for A/S decreases in an age-dependent fashion, with a small cadre of older children having difficulty enough with sustained immobilization that $A / S$ is necessary. In our experience, there is no difference in $\mathrm{A} / \mathrm{S}$ requirement by gender.
\end{abstract}

Keywords: Pediatric, Radiotherapy, Anesthesia requirement, Gender, Age

\section{Introduction}

The outpatient delivery of radiation therapy (RT) for children receiving daily anesthesia and/or sedation presents significant challenges. We have previously reported that repetitive daily anesthesia/sedation (A/S) may be provided safely to these children treated at free standing centers remote from hospital support, with low risk of complication or hospitalization [1]. We have also reported on the typical venous access devices and complication rates of each associated with their use in this milieu [2].

Factors requiring use of A/S to facilitate RT are poorly defined, varying on an individual basis. Such factors include, but may not be limited to: airway management, postoperative complications, cognitive function, emotional maturity, pain, musculoskeletal deformities, claustrophobia, and fear of the environment of treatment. Patients requiring RT frequently are immobilized in

\footnotetext{
* Correspondence: Peter.Johnstone@Moffitt.org

'IU Health Proton Therapy Center, Bloomington, Indiana

${ }^{3}$ Department of Radiation Oncology, Moffitt Cancer Center \& Research Institute, Tampa, Florida, USA

Full list of author information is available at the end of the article
}

restraint devices that create anxiety that may require A/ $\mathrm{S}$ to ensure accurate RT delivery.

Indiana University Health Proton Therapy Center (IUHPTC) has established expertise in treating pediatric patients in the outpatient setting [1]. In center, pediatric patients are assessed for $\mathrm{A} / \mathrm{S}$ by the attending radiation oncologist after evaluation and consultation with the patient and caregiver(s). The decision to pursue either general anesthesia or intravenous sedation in the delivery of care adds several levels of complexity to the care course including anesthesia risks, risks of daily manipulation of venous access devices [3-6], increased treatment delivery time, requirement for anesthesia recovery teams and space, increased cost due to anesthesia billings, and scheduling constraints on the entire department due to patient NPO needs requiring early treatments.

Treatment centers offering A/S have little formal guidance on selection of patients short of physician experience based on the treatment and setup required. However, staff planning, scheduling of other patients and center anesthesia services all require significant advance notice of $\mathrm{A} / \mathrm{S}$ requirements. To contribute to the scarce literature on the subject, this manuscript 
Table 1 Patient demographics by age and gender at time of radiotherapy delivery

\begin{tabular}{lllll}
\hline Age & \# Boys & Boys w/A/S & \# Girls & Girls w/A/S \\
\hline $\mathbf{1}$ & 9 & 9 & 12 & 12 \\
$\mathbf{2}$ & 18 & 18 & 25 & 25 \\
$\mathbf{3}$ & 15 & 15 & 17 & 17 \\
$\mathbf{4}$ & 13 & 13 & 16 & 15 \\
$\mathbf{5}$ & 18 & 17 & 8 & 7 \\
$\mathbf{6}$ & 15 & 6 & 10 & 8 \\
$\mathbf{7}$ & 16 & 8 & 12 & 5 \\
$\mathbf{8}$ & 9 & 4 & 14 & 7 \\
$\mathbf{9}$ & 5 & 2 & 8 & 3 \\
$\mathbf{1 0}$ & 8 & 3 & 9 & 1 \\
$\mathbf{1 1}$ & 8 & 1 & 9 & 2 \\
$\mathbf{1 2}$ & 11 & 0 & 7 & 2 \\
$\mathbf{1 3}$ & 15 & 0 & 5 & 0 \\
$\mathbf{1 4}$ & 9 & 0 & 10 & 1 \\
$\mathbf{1 5}$ & 15 & 2 & 12 & 0 \\
$\mathbf{1 6}$ & 13 & 1 & 7 & 1 \\
$\mathbf{1 7}$ & 11 & 1 & 9 & 1 \\
$\mathbf{1 8}$ & 0 & - & 1 & 0 \\
\hline
\end{tabular}

Parameters of the study population.

describes practical aspects of our experience with $\mathrm{RT}$ to pediatric patients. We have used these data to adapt A/S use and optimize pediatric scheduling at our facility.

\section{Methods}

After approval by the Indiana University Institutional Review Board, the records of the IUHPTC were screened for pediatric ( $\leq 18$ years of age) patients receiving $\mathrm{A} / \mathrm{S}$ with proton therapy at our center between 9 September 2004 and 30 June 2013. Subjects who underwent daily
A/S during any portion of their RT were identified and classified by gender and age. Particulars of the children receiving GA have been published previously [1].

\section{Results}

390 pediatric patients were treated within the study period, $182(47 \%)$ were girls. Patient demographics are collated in Table 1 and Figure 1.

Data review revealed $100 \%$ of patients aged $\leq 3$ years of age required $\mathrm{A} / \mathrm{S}$. This decreased by age, with about half of patients aged $7-8$ being able to undergo RT without support. Pediatric patients aged $\geq 13$ years still had $\sim 10 \%$ rate of $\mathrm{A} / \mathrm{S}$ requirement, and that there was no statistically different rate of $\mathrm{A} / \mathrm{S}$ use by gender.

\section{Discussion}

Due to complexity of care, pediatric RT treatments are typically delivered by facilities associated with academic teaching hospitals and tertiary care children's hospitals. As discussed in our previous reviews of our pediatric practice [1,2], the location of IUHPTC over 50 miles away from Riley Children's Hospital and 3 miles from IU Health Bloomington Hospital mandates that structured teamwork and training be continuously practiced. The addition of $\mathrm{A} / \mathrm{S}$ to an alreadychallenging pediatric RT treatment course adds marked complexity. The burden on patients of NPO requirements, and the potential disruption to clinic treatment flow and efficiency mandates extensive preplanning, and proton therapy centers must individually establish efficient workflow to decrease the burden on the entire system $[7,8]$. Thus, we performed this analysis to identify age and gender patterns as a first step in establishing patterns of $\mathrm{A} / \mathrm{S}$ use by demographic factors. While we did not specifically track adverse events in this population dating to 2004, informal discussion with staff personnel

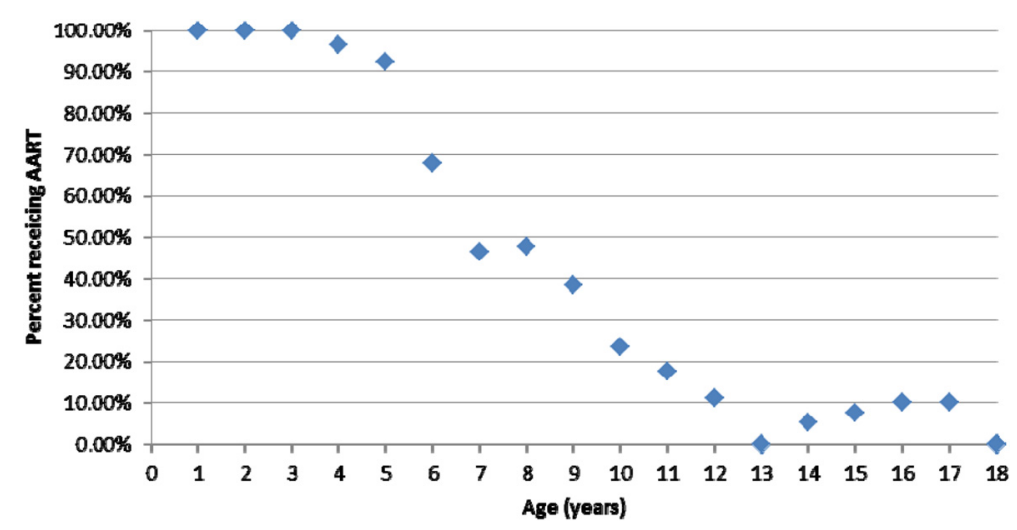

Figure 1 Graphical representation of percentage of patients requiring GA for radiotherapy treatment (Y-axis) based on age at time of treatment ( $x$-axis). 
did not reveal additional events besides those previously reported [1].

These data reveal that GA use is necessary in all patients age 3 and younger, with an age-dependent decrease until age 13 (Figure 1). These data are consistent with limited data in the anesthesia literature assessing pre-operative anxiety. In a prospective study by Kim and associates [9], age, type of parent or guardian, number of siblings, waiting time and score on the modified Yale Preoperative Anxiety Scale (mYPAS) were assessed for predicting need for pre-operative sedation for anxiety in children prior to general anesthesia (GA). In multivariate analysis, age, mYPAS score and waiting time were significant factors related to anxiety levels requiring preoperative sedation. The authors noted the same age-dependent pattern of decreasing need for pre-operative sedation and also the same lack of difference by gender as noted in our series. Zeev and colleagues [10] identified parent anxiety, child temperament, age and previous medical experiences as factors increasing child anxiety before GA. Methods to decrease child anxiety should be considered to facilitate their RT without A/S. Such strategies may be employed with little burden to the system.

Non-medication strategies to relieve preoperative anxiety and decrease the need for A/S have been reported. These strategies vary widely and include cartoon viewing [11], hand-held video game play [12], and presence of clown doctors [13]. While novel, these are admittedly impossible to correlate with daily RT delivery. Other strategies such as Child Life staffing [14] to employ interactive strategies have been reported as successful in the diagnostic imaging milieu and merit prospective evaluation in pediatric RT delivery.

One simple parameter that should be considered when considering $\mathrm{A} / \mathrm{S}$ in any pediatric RT patient is the complexity of the setup. Our clinic has extensive experience with supine craniospinal (CSI) RT. In our prior time study of the development of the technique [15], we documented that, even after documentation of team facility with any patient, average setup and treatment times for the four required fields remained just under one hour. If patients require CSI, that benchmark should be kept in mind. Although most older children will be able to tolerate one hour without $\mathrm{A} / \mathrm{S}$, about half of children 10 or older requiring $\mathrm{A} / \mathrm{S}$ in our experience did so for CSI fields. However, the converse should be kept in mind: younger patients requiring single fields or less complex setups may be able to lie still without A/S for the shorter times involved. This allows the clinic to reserve the limited anesthesia resources for the children that really need them. In our experience, treating pediatric patients in general is done at a considerable financial loss [16]. Minimizing the costs inherent in A/S can only ameliorate that problem.

\section{Conclusions}

In pediatric $\mathrm{RT}, \mathrm{A} / \mathrm{S}$ adds substantial burden to the patient and system, mandating factors predicting its necessity be identified. In children receiving daily RT, need for $\mathrm{A} / \mathrm{S}$ decreases in an age-dependent fashion after the age of 3, without a gender effect. About $10 \%$ of children 12 or older still require A/S.

\section{Competing interests}

The authors declare that they have no competing interests.

\section{Authors' contributions}

PJ provided concept. JB and TH collected data. TH, KB \& PJ provided data analysis. TH contributed the first draft with subsequent editing by KP \& PJ. All authors read and approved the final manuscript

\section{Authors' information}

Indiana University Institutional Review Board approval was obtained prior to data collection and analysis for this study.

\section{Acknowledgements}

Portions of this report were presented in poster form at the American Radium Society 96th Annual Meeting, St. Thomas, USVI, 26-30 Apr 2014

\section{Précis}

For children receiving daily radiotherapy, the need for anesthesia/sedation (A/S) decreases in an age-dependent fashion after the age of 3, without a gender effect. About $10 \%$ of children 12 or older still require A/S.

\section{Author details}

${ }^{1}$ IU Health Proton Therapy Center, Bloomington, Indiana. ${ }^{2}$ Department of Radiation Oncology, Indiana University School of Medicine, Indianapolis, Indiana, USA. ${ }^{3}$ Department of Radiation Oncology, Moffitt Cancer Center \& Research Institute, Tampa, Florida, USA.

Received: 5 June 2014 Accepted: 18 February 2015

Published online: 11 March 2015

\section{References}

1. Buchsbaum JC, McMullen KP, Douglas JG, Jackson JL, Simoneaux RV, Hines $M$, et al. Repetitive pediatric anesthesia in a non-hospital setting. Int J Radiat Oncol Biol Phys. 2013;85:1296-300.

2. Bratton J, Johnstone PAS, McMullen KP. Outpatient management of vascular access devices in children receiving radiotherapy: Complications and morbidity. Ped Blood Cancer. In press.

3. Richardson D, Bruso P. Vascular access devices. J Intraven Nurs. 1993;16:44-9.

4. Graham D, Keldermans M, Klemm L, Semenza N, Shafer M. Infectious complications among patients receiving home intervenaous therapy with peripheral, central, or peripherally placed central venous catheters. Am J Med. 1991;91:3B95S-100.

5. Walshe L, Malak S, Eagan J, Sepkowitz K. Complication rates among cancer patients with peripherally inserted central catheters. J Clin Oncol. 2002;20:3276-81

6. Babu R, Spicer RD. Implanted vascular access devices (Ports) in children: complications and their prevention. Pediatric Surg Int. 2002;18:50-3.

7. Combs SE, Kessel KA, Herfarth K, Jensen A, Oertel S, Blattmann C, et al. Treatment of pediatric patients and young adults with particle therapy at the Heidelberg lon Therapy Center (HIT): establishment of workflow and initial clinical data. Radiat Oncol. 2012;7:170.

8. Owusu-Agyemang P, Grosshans D, Arunkumar R, Rebello E, Popovich S, Zavala A, Williams C, Ruiz J, Hernandez M, Mahajan A, Porche V. Non-invasive anesthesia for children undergoing proton therapy. Radiother Oncol Feb 20, 2014. doi: 10.1016/j.radonc.2014.01.016. [epub ahead of print]

9. Kim J, Jo B, Hm O, Choi H, Lee Y. High anxiety, young age and long waits increase the need for preoperative sedatives in children. J Int Med Res. 2012;40:1381-9.

10. Kain ZN, Mayes LC, O'Connor TZ, Cicchetti DV. Preoperative anxiety in children: predictors and outcomes. Arch Pediatr Adolesc Med. 1996;150 (12):1238-45. 
11. Lee J, Lee J, Lim H, Son JS, Lee JR, Kim DC, et al. Cartoon distraction alleviates anxiety in children during induction of anesthesia. Anesth Analg. 2012;115:1168-73.

12. Patel A, Schieble T, Davidson M, Tran MC, Schoenberg C, Delphin E, et al Distraction with a hand-held video game reduces pediatric preoperative anxiety. Paediatr Anaesth. 2006;16(10):1019-27.

13. Vagnoli L, Caprilli S, Robiglio A, Messeri A. Clown doctors as a treatment for preoperative anxiety in children: a randomized, prospective study. Pediatrics. 2005;116(4):e563-7.

14. Kain ZN, Caramico LA, Mayes LC, Genevro JL, Bornstein MH, Hofstadter MB. Preoperative preparation programs in children: a comparative examination. Anesth Analg. 1998;87:1249-55.

15. Singhal M, Vincent A, Simoneaux V, Johnstone PAS, Buchsbaum JC. Overcoming the learning curve in supine pediatric proton craniospinal irradiation. J Am Coll Radiol. 2012;9:285-7.

16. Johnstone PAS, Kerstiens J. Doing poorly by doing good: the bottom line of proton therapy for children. J Am Coll Radiol. 2014;11:995-7.

\section{Submit your next manuscript to BioMed Central and take full advantage of:}

- Convenient online submission

- Thorough peer review

- No space constraints or color figure charges

- Immediate publication on acceptance

- Inclusion in PubMed, CAS, Scopus and Google Scholar

- Research which is freely available for redistribution 